\title{
Prescripciones de antibióticos para patologías bucodentales
}

Viviana E. Karaben ${ }^{\star}$ PhD. ${ }_{1}$, Ana E. Rea, Od.. ${ }_{1}$ Lelia I. Ramírez, Od.

Universidad Nacional del Nordeste, Corrientes, Argentina

Recibido: 28 de octubre del 2015 Aprobado: 7 de febrero del 2017

*Autor de correspondencia: Viviana Karaben. Facultad de Odontología unNE, Corrientes, Argentina, CP 3400 Av. Libertad 5450. Teléfono: 03794 473926. Correo electrónico: vekaraben@odn.unne.edu.ar, vivkaraben@hotmail.com

Cómo citar este artículo: Karaben VE, Rea AE, Ramírez LI. Prescripciones de antibióticos para patologías bucodentales. Rev Nac Odontol. 2017;13(25):67-76. doi: http://dx.doi.org/10.16925/od.v13i25.1883

Resumen. Introducción: se considera a los medicamentos como instrumentos terapéuticos y preventivos valiosos; sin embargo, no hay medicamento exento de riesgo, todos tienen efectos secundarios, algunos de ellos con consecuencias graves como el aumento creciente de la resistencia antimicrobiana. En este trabajo, se analizaron las diferentes indicaciones para las que fueron prescritos antimicrobianos por odontólogos, a fin de elaborar medidas de intervención que ayuden a lograr el uso racional de estos. Métodos: se analizaron todas las recetas de antimicrobianos recibidas durante doce meses en la farmacia de un instituto de servicio social; las recetas de prescripción contenían datos de medicamentos, dosis, cantidad y diagnóstico. Se realizó el análisis crítico de las prescripciones de acuerdo con aspectos cuantitativos y cualitativos. Resultados: el antibiótico más prescrito fue azitromicina, seguido de amoxicilina con ácido clavulánico; no obstante, la literatura científica recomienda las penicilinas como primera elección en el tratamiento farmacológico de patologías bucodentales, siendo la azitromicina reservada para alergia a la amoxicilina. Los medicamentos prescritos desde el punto de vista cualitativo son de valor terapéutico elevado, cuando existen grupos de medicamentos que no son de elección para patologías dentarias, macrólidos (claritromicina y azitromicina), cefalosporinas de tercera generación (ceftriaxona, etc.) y quinolonas (ciprofloxacina y levofloxacina). Conclusión: debemos tomar conciencia de la importancia del uso racional de los antibióticos en la práctica clínica dental, en busca de un tratamiento exitoso, minimizando los efectos secundarios y la aparición de resistencia a estos.

Palabras clave: antibacterianos, antibióticos, prescripción, uso racional de medicamentos. 


\title{
Antibiotic prescriptions for oral pathologies
}

\begin{abstract}
Introduction: Drugs are regarded as valuable therapeutic and preventive instruments; however, there are no risk-free drugs. All of them have side effects, and some have serious consequences such as increased antimicrobial resistance. In this work, the different indications for which antimicrobials were prescribed by dentists were analyzed, in order to take intervention measures that help to achieve their rational use. Methods: All the antimicrobial prescriptions received during twelve months by the drugstore of a social service institute were analyzed; the prescriptions contained data on medications, dosage, quantity and diagnosis. The critical analysis of the prescriptions was made according to quantitative and qualitative aspects. Results: The most prescribed antibiotic was azithromycin, followed by amoxicillin/clavulanic acid; however, the scientific literature recommends penicillins as the first choice in the pharmacological treatment of oral pathologies, with azithromycin being reserved for allergy to amoxicillin. Drugs prescribed from the qualitative point of view are of high therapeutic value, when there are groups of drugs that are not of choice for dental pathologies, macrolides (clarithromycin and azithromycin), third generation cephalosporins (ceftriaxone, etc.) and quinolones (ciprofloxacin and levofloxacin). Conclusion: We must become aware of the importance of the rational use of antibiotics in the dental clinical practice when looking for a successful treatment that minimizes side effects and drug resistance.
\end{abstract}

Keywords: antibacterials, antibiotics, prescription, rational use of drugs.

\section{Prescrições de antibióticos para patologias bucodentais}

Resumo. Introdução: consideram-se os medicamentos como instrumentos terapêuticos e preventivos valiosos; contudo, não há medicamento isento de risco, todos têm efeitos secundários; alguns deles com consequências graves como o aumento crescente da resistência antimicrobiana. Neste trabalho, foram analisadas as diferentes indicações para as quais foram prescritos antimicrobianos por odontólogos, a fim de elaborar medidas de intervenção que ajudem a conseguir o uso racional destes. Métodos: analisaram-se todas as receitas de antimicrobianos recebidas durante 12 meses na farmácia de um instituto de serviço social; as receitas de prescrição continham dados de medicamentos, doses, quantidade e diagnóstico. Foi realizada a análise crítica das prescrições de acordo com aspectos quantitativos e qualitativos. Resultados: o antibiótico mais receitado foi azitromicina, seguido de amoxicilina com ácido clavulânico; no entanto, a literatura científica recomenda as penicilinas como primeira escolha no tratamento farmacológico de patologias bucodentais, sendo a azitromicina reservada para alergia à amoxicilina. Os medicamentos prescritos do ponto de vista qualitativo são de valor terapêutico elevado, quando existem grupos de medicamentos que não são de escolha para patologias dentárias, macrólidos (claritromicina e azitromicina), cefalosporinas de terceira geração (ceftriaxona etc.) e quinolonas (ciprofloxacina e levofloxacina). Conclusão: devemos conscientizar-nos da importância do uso racional dos antibióticos na prática clínica dental, em busca de um tratamento bem-sucedido, que minimize os efeitos secundários e o surgimento de resistência a estes.

Palavras-chave: antibacterianos, antibióticos, prescrição, uso racional de medicamentos. 


\section{Introducción}

Se considera que los medicamentos son instrumentos terapéuticos y preventivos valiosos [1]; sin embargo, no hay medicamento exento de riesgo y todos tienen efectos secundarios de mayor o menor importancia [2]. Los estudios de utilización de medicamentos (EUM) son herramientas útiles para el análisis de situación, a fin de conocer cómo se utilizan los medicamentos en una población, en qué pacientes y con qué indicaciones, con la intención de establecer objetivos de mejora [3-5].

En relación con la utilización de antimicrobianos, se estima que el $10 \%$ de las prescripciones antibióticas están relacionadas con la infección odontogénica [6-8]. En odontología se realiza, por lo general, una prescripción empírica basada en epidemiología clínica y bacteriana, sin confirmar - en la mayoría de los casos- el diagnóstico por examen microbiológico [9].

La infección odontogénica típica es considerada mixta, compuesta por gérmenes aerobios y anaerobios [10], predominando unos sobre otros en determinadas circunstancias. Los antibióticos con efectividad en la práctica dental son aquellos con actividad frente a microorganismos aerobios y anaerobios tanto facultativos como estrictos; por lo tanto, es importante resaltar que para la selección de antibióticos en el tratamiento de infecciones bucodentales - además del tipo de patología infecciosa a tratar y de las condiciones generales del paciente-, se deben tener en cuenta las características particulares del antimicrobiano como eficacia, espectro de acción, comodidad en la administración y seguridad del medicamento (que implica que debe tener la menor posibilidad de producir efectos adversos) [11].

De acuerdo con las características particulares de la patología a tratar y del paciente, el tratamiento óptimo podría ser de índole mecánica-quirúrgica, farmacológica o una combinación de estas $[6,11$, 12]. La patología infecciosa debe tratar de resolverse con el tratamiento odontológico propiamente dicho [13], dado que los antimicrobianos innecesarios aumentan el riesgo de efectos adversos y la resistencia bacteriana [14]; es decir, que no representan el principal tratamiento para erradicar la infección, a no ser que haya síntomas y signos clínicos de un proceso infeccioso en pacientes con estado general afectado, hipertermia mayor a $37,8^{\circ} \mathrm{C}$, linfoadenopatía regional, asimetría facial y pacientes inmunodeprimidos [15]. Al indicar el tratamiento antimicrobiano como complemento, se evitaría la extensión local y la contigüidad de la infección, lo que prevendría las complicaciones derivadas de la diseminación hematógena $[6,11,16-18]$.

La aparición de especies bacterianas resistentes a los antibióticos obliga a tomar conciencia de la importancia de restringir el uso de antibióticos para casos justificados de infección severa [19]. Tal es así que recientemente la Organización Mundial de la Salud (oms) emitió un reporte global de vigilancia sobre la resistencia a los antimicrobianos, en el cual se expone el estado de alarma que supone el marcado aumento de resistencia a los antibióticos, sumado a la falta de innovaciones terapéuticas para patologías de índole infecciosa [20].

La resistencia bacteriana puede derivarse del uso inadecuado e irracional de los antimicrobianos, que crea condiciones favorables a la aparición y propagación de microorganismos resistentes; por ejemplo, cuando los pacientes no realizan el tratamiento completo con el antimicrobiano recetado o cuando dicho medicamento es de mala calidad [21]. A la vez, los profesionales de la salud también pueden contribuir a la aparición de resistencia bacteriana al prescribir antibióticos sin una indicación precisa y adecuada.

La odontología es un área en la cual se presentan situaciones de uso indiscriminado, lo que hace pertinente el estudio de la situación, sobre todo teniendo en cuenta que los antibióticos son fármacos que afectan tanto al paciente que los consume como a poblaciones enteras a través de los efectos colectivos que producen en la ecología microbiana [22].

En el presente trabajo, se analizaron las diferentes indicaciones para las que fueron prescritos antibióticos. Esto con el fin de evaluar la relación entre medicamentos recetados y el diagnóstico, además de diseñar - si fuera necesario- estrategias de mejora para el uso racional de los medicamentos.

\section{Métodos}

Se trata de un estudio observacional, descriptivo y longitudinal, de una muestra conformada por 702 recetas de prescripción de medicamentos realizadas por odontólogos, obtenidas en un instituto de servicio social (Issunne) de la ciudad de Corrientes, en Argentina. En el análisis, fueron incluidas todas 
las recetas recibidas durante doce meses continuos en el 2013. Los criterios de inclusión son recetas elaboradas por odontólogos, con prescripción de antibióticos; y los criterios de exclusión son: recetas ilegibles o incompletas y recetas elaboradas por otro profesional de la salud. Se destaca que no existían campañas de uso de medicamentos ni pautas obligatorias de prescripción, con lo que se descartan posibles sesgos en la prescripción espontánea de medicamentos en los profesionales odontólogos.

Se cuenta con aprobación del Comité de Bioética de la Facultad de Odontología de la unNe, bajo Resolución 315/13 CD.

Entre la clasificación de EUM, es de tipo prescripción-indicación, en el que se describen las indicaciones para las cuales se utiliza un determinado fármaco o grupo de fármacos $[1,5]$.

\section{Marco muestral}

Se considera prescripción toda receta elaborada por un profesional odontólogo para tratar patologías bucodentales y presentada a la farmacia de la Issunne a fin de obtener el medicamento explicitado, sin tener el equipo de trabajo de intervención en la atención del paciente y/o prescripción de los medicamentos. De acuerdo con pautas bioéticas, se preserva el nombre del paciente y de quien prescribe.

El análisis crítico de las prescripciones se efectuó de acuerdo con aspectos cuantitativos y cualitativos. Para el análisis cuantitativo de la prescripción de los medicamentos, se tuvo en cuenta la clasificación Anatómica-Terapéutica-Química (ATC), que es un sistema recomendado por el Drug Utilization Research Group (DURG) de la OMs para asignar nomenclatura a los medicamentos, en el que se asigna un código a cada fármaco según el sistema u órgano en el que ejercen su acción principal. A partir de la codificación de los medicamentos, se utilizó estadística descriptiva para determinar la frecuencia de uso de medicamentos para cada diagnóstico. El análisis de cada patología dentaria se hizo en relación con la frecuencia de los diferentes medicamentos utilizados, y teniendo en cuenta la dosis diaria prescrita y la duración del tratamiento en relación con el diagnóstico.
En cuanto al análisis y la valoración cualitativa, se realizó a través del Valor Intrínseco Terapéutico Potencial. Se consideran de valor terapéutico potencial elevado todos aquellos medicamentos que tienen eficacia y seguridad demostrada en ensayos clínicos, que posean indicaciones definidas, además con efectos inmediatos y obvios. Y se consideran de valor terapéutico potencial no elevado todos aquellos medicamentos cuya eficacia terapéutica no ha sido demostrada en ensayos clínicos controlados para las indicaciones anunciadas, ya sean monofármacos o medicamentos en combinación a dosis fijas que por sus características farmacológicas conllevan una relación de beneficio-riesgo totalmente desfavorable para el paciente.

Para determinar la adecuación en la relación del medicamento con el diagnóstico y la dosis, se contrastó la información de los medicamentos prescritos con el Formulario Terapéutico Nacional de la Confederación Médica de la República Argentina (Comra) [23], que contiene un listado de medicamentos avalados por estudios sobre eficacia y seguridad, conjuntamente con el Formulario Nacional Británico (BNF) [24].

\section{Resultados}

Durante los doce meses del estudio, se observaron 702 recetas confeccionadas por odontólogos, y se analizaron 387 (55\%) que correspondían a prescripciones de antibióticos.

En la tabla 1, se consigna el tipo de antibiótico con su Denominación Común Internacional (DCI) y su frecuencia absoluta.

Del total de prescripciones de antibióticos, se observa en combinación a dosis fija $(n=102)$, que son aquellos medicamentos que contienen dos o más principios activos en la misma formulación, como se detalla en la tabla 1.

En cuanto a los diferentes diagnósticos que recibieron antibióticos como tratamiento farmacológico, la distribución puede observarse en la figura 1.

En las figuras 1-5, se observa el análisis de las prescripciones de medicamentos en relación con los diagnósticos. 
Tabla 1. Frecuencia de prescripción de antibióticos por odontólogos

\begin{tabular}{|c|c|c|c|c|}
\hline $\begin{array}{l}\text { Antimicrobianos } \\
\qquad \mathbf{n}=\mathbf{3 8 7}\end{array}$ & DCI & $f a$ & $f r$ & $\%$ \\
\hline \multirow{15}{*}{ Antibióticos } & Azitromicina & 176 & 0,455 & 45,5 \\
\hline & Amoxicilina + ácido clavulánico & 98 & 0,253 & 25 \\
\hline & Amoxicilina & 81 & 0,21 & 21 \\
\hline & Ampicilina & 8 & 0,021 & 2,1 \\
\hline & Cefalexina & 4 & 0,01 & 1 \\
\hline & Ceftriaxona & 4 & 0,01 & 1 \\
\hline & Claritromicina & 3 & 0,008 & 0,8 \\
\hline & Eritromicina & 3 & 0,008 & 0,8 \\
\hline & Amoxicilina + Diclofenac & 3 & 0,008 & 0,8 \\
\hline & Metronidazol & 2 & 0,005 & 0,53 \\
\hline & Ciprofloxacina & 2 & 0,005 & 0,53 \\
\hline & Levofloxacina & 1 & 0,002 & 0,26 \\
\hline & Penicilina G & 1 & 0,002 & 0,26 \\
\hline & Sulfametoxazol + Trimetoprima & 1 & 0,002 & 0,26 \\
\hline & Total & 387 & 1 & $100 \%$ \\
\hline
\end{tabular}

Fuente: elaboración propia

\section{Indicaciones odontológicas de tratamiento antibiótico n=336}

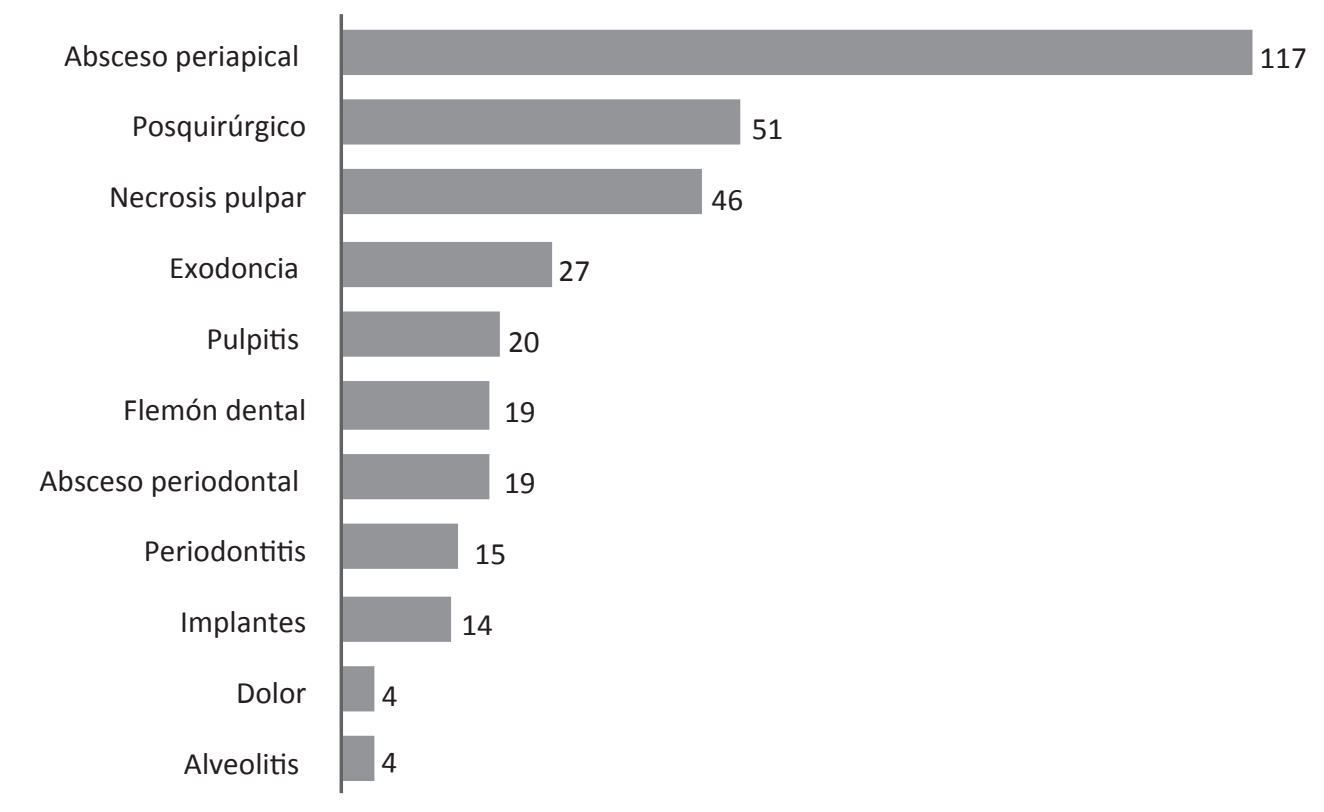

Figura 1. Patologías dentarias con prescripción de antibióticos

Fuente: elaboración propia 


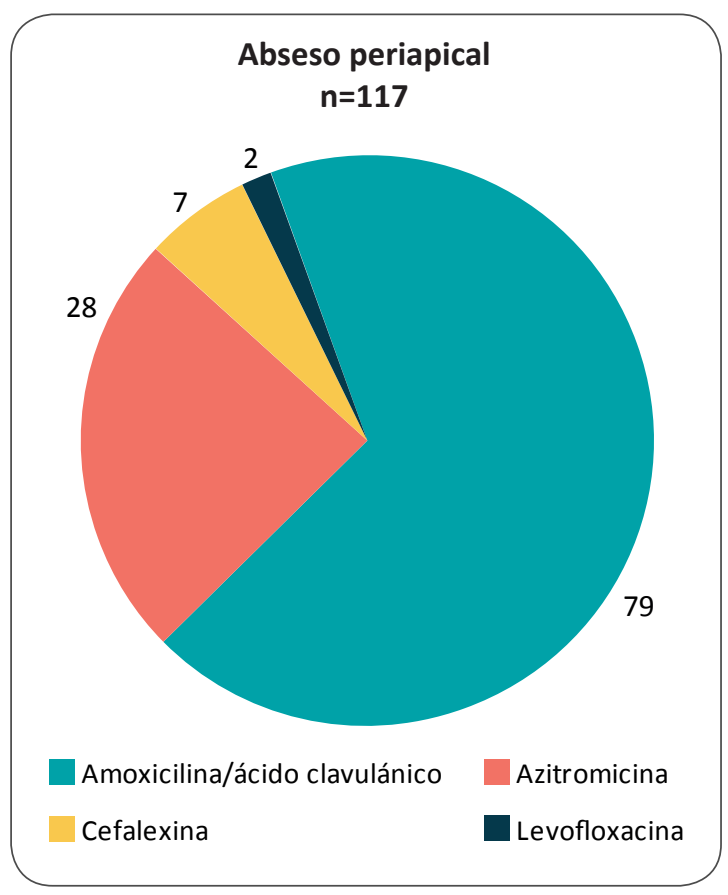

Figura 2. Frecuencia de antibióticos prescritos para absceso periapical

Fuente: elaboración propia

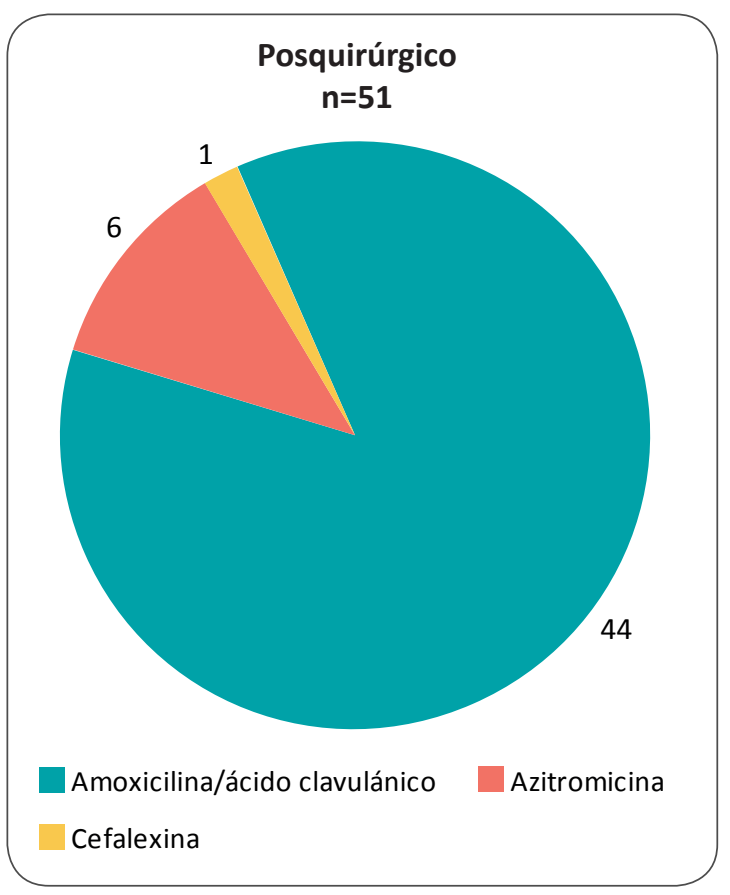

Figura 3. Frecuencia de antibióticos prescritos para diagnóstico posquirúrgico

Fuente: elaboración propia

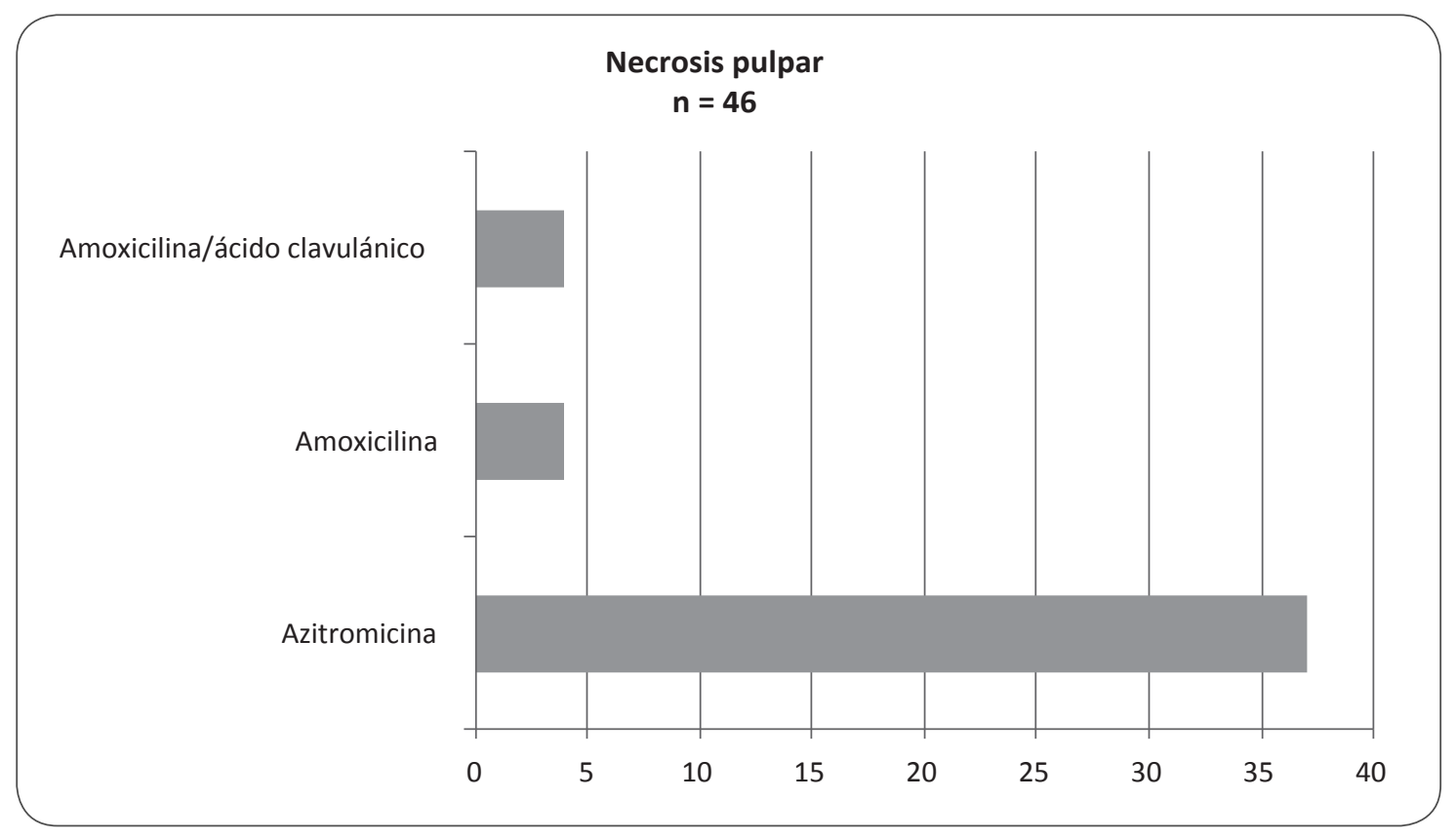

Figura 4. Frecuencia de antibióticos prescritos para necrosis dental Fuente: elaboración propia 

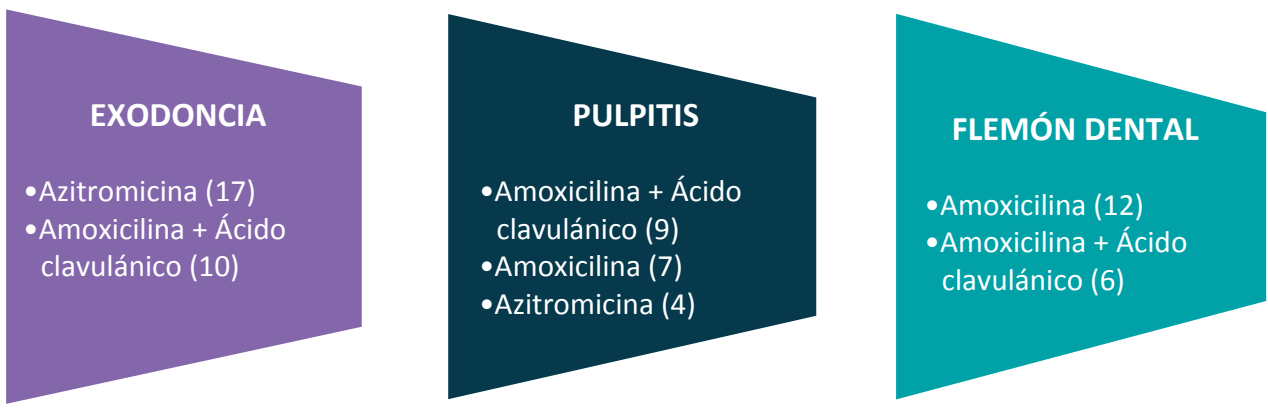

Figura 5. Frecuencia de antibióticos prescritos para exodoncia, pulpitis y flemón dental Fuente: elaboración propia

Sin embargo, el test estadístico chi cuadrado ( $\mathrm{p}$ 0,83) refiere que no hay diferencia estadísticamente significativa en relación con la adecuación, aunque es de relevancia clínica analizar puntualmente los casos considerados inadecuados. De las recetas innecesarias, se registró la prescripción de antibiótico para dolor en cuatro oportunidades, dos de azitromicina y dos de amoxicilina con ácido clavulánico. En el caso de alveolitis, se observó la prescripción de ceftriaxona (2), azitromicina (1) y amoxicilina con ácido clavulánico (1); en esta indicación junto a los antimicrobianos se prescribió en dos ocasiones analgésicos como diclofenac y flurbiprofeno (1).

Para la valoración de prescripción adecuada, se relaciona el medicamento con el diagnóstico, la dosis y la duración del tratamiento. A partir del análisis de los medicamentos prescritos, se observaron algunos con indicaciones no establecidas en formularios terapéuticos, los cuales se detallan en la tabla 2 .

La azitromicina registró mayor prescripción para diagnósticos como el posquirúrgico, la necrosis dental, la exodoncia y la profilaxis prequirúrgica. En cuanto a la duración del tratamiento con azitromicina, osciló entre tres y cinco días de tratamiento. Para amoxicilina, de un total de 81 prescripciones, se observó en 44 oportunidades la prescripción para menos de cinco días de tratamiento.

De acuerdo con el análisis cualitativo, el valor intrínseco terapéutico potencial actúa como un indicador de la calidad de los medicamentos prescritos, en el que se considera de valor elevado: al valor 1 con medicamentos de eficacia y seguridad
Tabla 2. Análisis de la relación de medicamentosdiagnóstico

\begin{tabular}{ccc}
\hline Antibiótico & Diagnóstico & Cantidad \\
\hline Ceftriaxona & Absceso periapical & 3 \\
Ceftriaxona & Alveolitis & 2 \\
Ciprofloxacina & Absceso periapical & 2 \\
Amoxicilina con & Dolor & 2 \\
ácido clavulánico & Dolor & 1 \\
Azitromicina & Absceso periapical & 1 \\
\hline
\end{tabular}

Fuente: elaboración propia

demostrada; y entre los considerados de valor no elevado se encuentran: el valor 2 (dudoso o nulo), el valor 3 (relativo) y el valor 4 (inaceptable).

En este estudio, se observó que los antibióticos prescritos fueron considerados de valor elevado; incluso, de las 102 combinaciones a dosis fija observadas, 98 correspondían a la asociación amoxicilina con ácido clavulánico, también considerada de valor elevado. Los medicamentos en combinación a dosis fija considerados de valor elevado, que además figuran en el Comra y el BNF, son amoxicilina con ácido clavulánico y sulfametoxazol con trimetoprima, que representan combinaciones racionales.

Entre los de valor inaceptable se observó la combinación a dosis fija de amoxicilina más diclofenac (3), que no presenta un equilibrio aceptable entre beneficio y riesgo del tratamiento farmacológico. 


\section{Discusión}

En el presente estudio, el antibiótico de elección fue azitromicina, seguida por amoxicilina y amoxicilina con ácido clavulánico, prescripciones que no coincidieron con guías y formularios terapéuticos como Comra y BNF, que recomiendan la amoxicilina como primera elección.

La Asociación Dental Americana (ADA), entre otras autoridades, considera la penicilina como fármaco de primera elección ante infecciones orales y periorales, específicamente la amoxicilina, y como alternativa considera la amoxicilina con ácido clavulánico. En pacientes alérgicos a la penicilina, la ADA recomienda eritromicina o clindamicina $[9,11$, 15, 25-29]. Sin embargo, para otros autores en los últimos años, la asociación de amoxicilina con ácido clavulánico resulta ser más apropiada, ya que permite restablecer la actividad del antibiótico ante las bacterias, manteniendo un amplio espectro de actividad $[7,18]$.

La escasa acción de las cefalosporinas de primera generación sobre bacterias anaerobias Gram negativas le restan validez para el tratamiento; no así la clindamicina, que es un agente eficaz por su espectro de acción ante los patógenos habituales de la boca y son de elección en pacientes alérgicos a betalactámicos [11, 18].

En cuanto a las patologías orales de origen infeccioso, la literatura ubica como más frecuente el absceso periapical, que supone aproximadamente el $63 \%$ de las afecciones de la cavidad bucal [9], seguida de la gingivitis (50\%) y la periodontitis (30\%) [11]

En este estudio, el diagnóstico más frecuente fue absceso periapical, seguido de posquirúrgico y gangrena dental. En caso de absceso periapical, el tratamiento farmacológico más frecuente se realizó con amoxicilina, en concordancia con una revisión sobre antibióticos que considera a la penicilina como primera opción para tratamiento antibiótico de patologías orales, recomendada en infecciones graves como celulitis facial [27].

Upegui Jiménez et al. [28] consideran que la amoxicilina sigue siendo el agente de primera línea en el tratamiento de infecciones periapicales y que la amoxicilina con ácido clavulánico, la clindamicina y el metronidazol son alternativas útiles contra bacterias anaerobias. Skucaite et al. [30] coinciden en considerar la amoxicilina en primer lugar y la clindamicina como alternativa en pacientes alérgicos [30].

En un estudio realizado por Rodríguez Alonso et al. [11], en el 2009, en Barcelona, 64 pacientes con infección odontogénica reportan la resistencia de bacterias anaerobias a la amoxicilina y a la amoxicilina con ácido clavulánico, sin encontrar diferencias significativas, por lo cual consideran la amoxicilina como antibiótico de elección, siendo la clindamicina y la amoxicilina con ácido clavulánico alternativas en fracasos o en pacientes alérgicos a la penicilina.

Una revisión sistemática de ocho ensayos clínicos, realizada por Matthews et al. [14] en el 2003, concluye que el tratamiento antibiótico no tiene beneficio adicional y debe ser indicado en casos de complicaciones sistémicas con fiebre, linfadenopatía o celulitis, y en pacientes inmunodeprimidos.

En relación con la prescripción antibiótica para profilaxis quirúrgica, un informe de actualización de Rodríguez Alonso y Rodríguez Monje [11] propone como indicación únicamente a pacientes inmunosuprimidos, con enfermedad sistémica grave o cardiopatías con riesgo de desarrollar endocarditis bacteriana, quienes deben ser indicados siempre de manera preoperatoria, siendo en este estudio la totalidad de indicación posquirúrgica.

En otro documento de consenso sobre la utilización de profilaxis antibiótica en cirugía, Gutiérrez et al. (2003) sugieren que está indicada solo cuando exista un riesgo importante de infección, por características propias de la intervención o por condiciones locales y/o generales del paciente [7].

Otros autores analizan diferentes guías clínicas internacionales sobre la necesidad de utilizar profilaxis antimicrobiana, y coinciden con las nuevas directrices de sociedades nacionales e internacionales que cuestionan el uso indiscriminado para la prevención de la endocarditis infecciosa. Sin embargo, aún se recomienda el uso de profilaxis previa en pacientes con alto riesgo, cuyo tratamiento dental conlleve sangrado [31, 32].

La resistencia a los antimicrobianos amenaza la prevención y el tratamiento eficaz de una gama cada vez mayor de infecciones causadas por bacterias, parásitos, virus y hongos. Un informe reciente, elaborado y publicado por la oms [20], señala que la resistencia a las bacterias comunes ha alcanzado niveles alarmantes en muchas partes del mundo y que en pocos lugares los tratamientos disponibles siguen siendo eficaces para las infecciones comunes. 


\section{Conclusión}

En este estudio, se observó la utilización de antimicrobianos eficaces, seguros y con escaso número de medicamentos en combinaciones irracionales. Sin embargo, la amplia utilización de azitromicina no coincide con las guías y protocolos de utilización de la literatura científica, en los cuales esta se reserva para casos de alergia a penicilina. Además, llama la atención el uso de otros grupos antibióticos que no son de primera elección para el tratamiento de patologías bucodentales, así como su utilización para diagnósticos en los que no es necesaria la medicación antibiótica.

Por encontrar situaciones de uso irracional de medicamentos, es necesario continuar el trabajo implementando una intervención educativa y analizar posteriormente el aporte de esta para lograr cambios en patrones prescriptivos de los profesionales de la salud.

\section{Referencias}

[1] Figueras A, Vallano A, Narváez E. Fundamentos metodológicos de los Estudios de Utilización de Medicamentos. Manual práctico. Managua: MINSA; 2003.

[2] World Health Organization. Fact sheet N. ${ }^{\circ} 293$. Medicines: safety of medicines-adverse drug reactions. Copenhagen: wHO; 2008.

[3] Iñesta García A. Atención farmacéutica, estudios sobre uso de medicamentos y otros. Rev Esp Salud Pública. 2001;75(4):285-90. doi: 10.1590/S1135-57 272001000400003

[4] López JJ, Garay AM. Estudio de utilización de antibióticos en el servicio de consulta externa de un hospital público en Bogotá, D.C. Rev Colomb Cienc Quím Farm. 2016;45(1):35-47. doi: 10.15446 /rcciquifa.v45n1.58014

[5] Laporte J-R, Tognoni G. Estudios de utilización de medicamentos y fármacovigilancia. En: Laporte JR, Tognoni G. (editores). Principios de epidemiología del medicamento. 2. ${ }^{a}$ edición. Barcelona: Ediciones Científicas y Técnicas; 1993.

[6] Bascones A, Aguirre JM, Bermejo A, Blanco A, Gay-Escoda C, Gónzález-Moles MA, et al. Documento de consenso sobre el tratamiento antimicrobiano de las infecciones bacterianas odontogénicas. Med Oral Patol Oral Cir Bucal. 2004;9:363-76. doi: $10.4321 / \mathrm{S} 0213-12852005000600004$
[7] Gutiérrez JL, Bagán JV, Bascones A, Llamas R, Llena J, Morales A, Noguerol B, et al. Documento de consenso sobre la utilización de profilaxis antibiótica en cirugía y procedimientos dentales. Rev Esp Cirug Oral y Maxilofac. 2006;28(3):151-81. doi: 10.4 321/s1130-05582006000300001

[8] Armiñanzas Castillo C, García Zornoza R, Arnáiz de las Revillas Almajano F. Protocolo diagnóstico y terapéutico de la infección oral y faríngea. Medicine - Programa de Formación Médica Continuada Acreditado. 2014;11(59):3515-9. doi: https://doi.org /10.1016/S0304-5412(14)70808-X

[9] Fuentes R, Weber B, Flores T, Oporto G. Uso de profilaxis antibiótica en implantes dentales: revisión de la literatura. Int J Odontostomat. 2010;4(1):5-8. doi: 10.4067/S0718-381X2010000100001

[10] Bravo Cordero G, Minzer Ferrer A, Fernández L. Sinusitis odontogénica, fístula oroantral y su reparación quirúrgica mediante colgajo de bolsa de Bichat: revisión de la literatura. Acta Otorrinolaringol Esp. 2016;67(2):107-13. doi: 10.1016/j.otorri.2015. 03.001

[11] Rodríguez-Alonso E, Rodríguez Monje MT. Tratamiento antibiótico de la infección odontogénica. Información Terapéutica del Sistema Nacional de Salud. 2009;33(3):67-79.

[12] González-Martínez R, Cortell-Ballester I, Herráez-Vilas JM, Arnau-de Bolós JM, Gay-Escoda C. Antibiotic prescription in the treatment of odontogenic infection by health professionals: A factor to consensus. Med Oral Patol Oral Cir Bucal. 2012;17 (3):e452-6. doi: 10.4317/medoral.17504

[13] Wannmacher L, Cardozo Ferreira MB. Principios generais do uso correto de antimicrobianos. En: Wannmacher L, Cardozo Ferreira MB. Farmacología clínica para dentistas. 2. ${ }^{a}$ edición. Río de Janeiro: Editorial GuanabaraKoogan; 1999. p.175-83.

[14] Cope A, Francis N, Wood F, Mann MK, Chestnutt IG. Systemic antibiotics for symptomatic apical periodontitis and acute apical abscess in adults. Cochrane Database of Systematic Reviews. 2014;26(6): CD010136. doi: 10.1002/14651858.CD010136.pub2

[15] Ferlini Filho J. Quimioterapia antimicrobiana em endodontia. En: Wannmacher L, Cardozo Ferreira MB. Farmacologia clínica para dentistas. 2. ${ }^{a}$ edición. Río de Janeiro: Editorial GuanabaraKoogan; 1999. p. 247-52.

[16] Sancho-Puchades M, Herráez-Vilas JM, Valmaseda-Castellón E, BeriniAytés L, Gay-Escoda C. Analysis of the antibiotic prophylaxis prescribed by Spanish Oral Surgeons. Med Oral Patol Oral Cir Bucal. 2009;14(10):e533-7. doi:10.4317/medoral.14.e533 
[17] Bidar M, Gharechahi M, Soleimani T, Eslami N. Survey over the dentists' and endodontists' approaches towards the management of endodontic emergencies in Mashhad, Iran. Iran Endod J. 2015;10(4):25662. doi: 10.7508/iej.2015.04.010

[18] Robles Raya P, Frutos Echaniz E, Moreno Millán N, Mas Casals A, Sánchez Callejas A, Morató Agustí ML. Me voy al dentista: ¿antibiótico como prevención o como tratamiento? Atenc Primaria. 2013;45(4):21621. doi: 10.1016/j.aprim.2012.10.006

[19] Lewis M. Why we must reduce dental prescription of antibiotics: European Union Antibiotic Awareness Day. British Dental Journal. 2008;205(10):5378. doi: 10.1038/sj.bdj.2008.984

[20] OMs - Organización Mundial de la Salud. Antimicrobial resistance: Global report on surveillance. [internet]. 2014. Disponible en: http://www.who.int/ drugresistance/documents/surveillancereport/en/

[21] OMs - Organización Mundial de la Salud. Resistencia a los antimicrobianos (RAM). Nota descriptiva N¹94 [internet]. 2012. Disponible en: http://www. who.int/mediacentre/factsheets/antibiotic-resistance/es/

[22] García-Rey C, Fenoll A, Aguilar L, Casal J. Effect of social and climatological factors on antimicrobialuse and Streptococcus pneumoniae resistance in different provinces in Spain. J Antimicrob Chemother. 2004;54(2):465-71. doi: 10.1093/jac/dkh375

[23] Comra - Confederación Médica de la República Argentina. Formulario Terapéutico Nacional. Confederación Médica de la República Argentina. 11. ${ }^{\mathrm{a}}$ edición. Buenos Aires: Editorial Comra; 2010.

[24] BNF - British National Formulary. British National Formulary. 2009;57:283-366.

[25] Clay W, Machion L. Antibióticos. En: Ada \& Thomson PDR. Guía ADA/PDR de terapéutica dental. 4 a $^{\mathrm{a}}$ edición. Madrid: Editorial Médica; 2009.

[26] Arteaga Bonilla R, Arteaga Michel R. Tratamiento de las infecciones odontogénicas. Rev Bol Ped. 2006;45(3):166-70.
[27] Buchelli J, Esteves MC, Rojas Páez PA. Antibióticos en el manejo de las infecciones odontogénicas de origen endodóntico. Rev Odontología Actual. 2008;6(61):38-52.

[28] Upegui Jiménez L, Molina Colorado D. Susceptibilidad antimicrobiana de microorganismos anaerobios aislados de infecciones endodónticas primarias a amoxicilina y metronidazol y su asociación con los parámetros clínicos: serie de casos. Int J Odontostomat. 2016;10(1):149-59. doi: 10.4067/S0718-381X2 016000100023

[29] Saeed Dar-Odeh N, Abdalla Abu-Hammad O, Khaled Al-Omiri M, Sameh Khraisat A, Shehabi A. Antibiotic prescribing practices by dentists: A review. Therapeutics and Clinical Risk Management. 2010;6:301-6. doi: 10.2147/TCRM.S9736

[30] Skucaite N, Peciuliene V, Vitkauskiene A, Machiulskiene V. Susceptibility of endodontic pathogens to antibiotics in patients with symptomatic apical periodontitis. J Endod. 2010;36(10):1611-6. doi: 10. 1016/j.joen.2010.04.009

[31] Bascones-Martínez A, Corcuera-Muñoz M, Bascones-Ilundain J. Infecciones orales y endocarditis bacteriana. MedClin (Barc). 2012;138:312-7. doi: 10. 1016/j.medcli.2011.03.029

[32] Habib G, Hoen B, Tornos P, Thuny F, Prendergast B, EsC Committee for Practice Guidelines, et al. Guidelines on the prevention, diagnosis, and treatment of infective endocarditis (new version 2009): The Task Force on the Prevention, Diagnosis, and Treatment of Infective Endocarditis of the European Society of Cardiology (ESC) endorsed by the European Society of Clinical Microbiology and Infectious Diseases (ESCMID) and by the International Society of Chemotherapy (ISC) for Infection and Cancer. Eur Heart J. 2009;30(19):2369-413 doi: 10.1093/eurheartj/ehp285 